\title{
Enhancing ORR performance of bimetallic PdAg electrocatalysts by designing interactions between $\mathrm{Pd}$ and $\mathrm{Ag}$
}

$\dagger$ Luis E. Betancourt, $\$$ Arnulfo Rojas-Pérez, †Ivan Orozco, $\dagger$ Anatoly I. Frenkel, $\dagger, \&$ Yuanyuan

Li\&, †Kotaro Sasaki, † Sanjaya D. Senanayake, and $\neq$ Carlos R. Cabrera*

$†$ Chemistry Division, Brookhaven National Laboratory, Upton, New York 11973

\&Department of Materials Science and Chemical Engineering, Stony Brook University, New

York, New York 11794, United States

†Department of Chemistry, University of Puerto Rico - Rio Piedras Campus, 17 Ave.

Universidad STE 1701, 6, San Juan, Puerto Rico 00925-2537

*Carlos R. Cabrera: carlos.cabrera2@upr.edu

\section{Table of Contents: Tables and Figures}

Table S1. Inductively coupled plasma-atomic emission spectroscopy (ICP-AES) analysis of catalyst materials.

Figure S1: Synthesis of Pd/Ag/C catalysts by galvanic displacement of upd $\mathrm{Cu}$. 2

Figure S2: Determination of the ORR RDE thermodynamic parameters of catalysts. 3

Figure S3: Rotating disk electrode (RDE) measurements of the oxygen reduction reaction catalysts4

Figure S4: Stability ORR polarization curves of the catalysts.

Figure S5: Cyclic voltammetry of Ag/C, adding a layer of Pd through the described synthetic method and (c) adding an additional layer of Ag. $\quad 6$

$\begin{array}{ll}\text { Figure S6: TEM and histogram for (a) Pd/C and (b) Ag/C catalysts. } & 7\end{array}$

Figure S7: $\mathrm{Pd} \mathrm{L}_{3}$-edge XANES systematics for the alloys relative to $\mathrm{Pd} / \mathrm{C}$ and a $\mathrm{Pd}\left(\mathrm{NO}_{3}\right)_{2}$ used as standard.

Figure S8: Pd $\mathrm{L}_{3}$-edge XANES spectra for the synthesized alloys without the $\mathrm{Cu}$ upd treatment relative to $\mathrm{Pd} / \mathrm{C}$ and a $\mathrm{Pd} @ \mathrm{Ag} / \mathrm{C}$.

Figure S9: XAFS data for (a) Pd edge and (b) Ag edge for all the catalysts examined.

Figure S10: Rotating disk electrode (RDE) measurements of the oxygen reduction reaction(ORR)10

Figure S11: Peak fitting of X-ray photoelectron spectroscopy of $\mathrm{Ag} \mathrm{3d}$ and Pd 3d binding energy peaks. 


\section{TABLES}

Table S1. Inductively coupled plasma-atomic emission spectroscopy (ICP-AES) analysis of catalyst materials

\begin{tabular}{|c|c|c|}
\hline Catalyst & $\begin{array}{c}\text { Ag concentration } \\
(\boldsymbol{\%} \mathbf{w t} \pm \mathbf{S t d})\end{array}$ & $\begin{array}{c}\text { Pd concentration } \\
(\boldsymbol{\%} \mathbf{w t} \pm \mathbf{S t d})\end{array}$ \\
\hline $\mathrm{Pd} @ \mathrm{Ag} / \mathrm{C}$ & $12.4 \pm 0.1$ & $10.3 \pm 0.3$ \\
\hline $\mathrm{Ag} @ \mathrm{Pd} / \mathrm{C}$ & $3.8 \pm 0.2$ & $18.9 \pm 0.3$ \\
\hline $\mathrm{Pd} / \mathrm{C}$ & $\mathrm{BDL}$ & $23.0 \pm 0.7$ \\
\hline $\mathrm{Ag} / \mathrm{C}$ & $35.5 \pm 0.3$ & $\mathrm{BDL}$ \\
\hline
\end{tabular}

Std: Standard deviation, BDL: Below detection limit

\section{FIGURES}

\section{Pd/Ag Core-Shell Potentials- Underpotential Deposition/Galvanic Displacement}

$\begin{array}{lr}\quad \text { Reaction } & \text { Reduction Potential } \\ \mathrm{Pd}^{2+}++2 \mathrm{e}^{-} \leftrightharpoons \mathrm{Pd} & \mathrm{E}^{\circ}=0.951 \mathrm{~V} \\ \mathrm{Ag}^{+}+\mathrm{e}^{-} \leftrightharpoons \mathrm{Ag} & \mathrm{E}^{\circ}=0.800 \mathrm{~V} \\ \mathrm{Cu}^{2+}+2 \mathrm{e}^{-} \leftrightharpoons \mathrm{Cu} & \mathrm{E}^{\circ}=0.340 \mathrm{~V}\end{array}$

\section{Pd/Ag Core-Shell Electrochemical/ Electroless Synthesis}

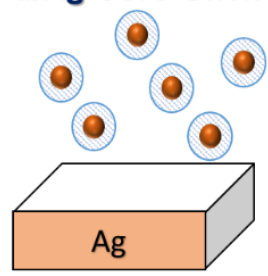

Underpotential deposition (UPD) of Cu monolayer on $\mathrm{Pd}$

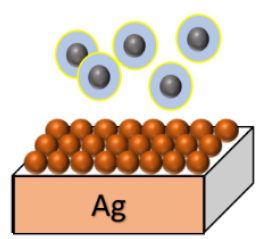

$$
\mathrm{Cu}_{\mathrm{UPD}} / \mathrm{Ag}+\mathrm{Pd}^{2+}
$$

Single Displacement Reaction (electroless)

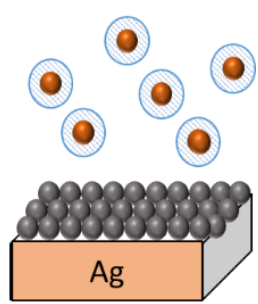

$\mathrm{Pd}_{\mathrm{ML}} / \mathrm{Ag}+\mathrm{Cu}^{2+}$

Figure S1: Synthesis of Pd/Ag/C catalysts by galvanic displacement of upd $\mathrm{Cu}$. 

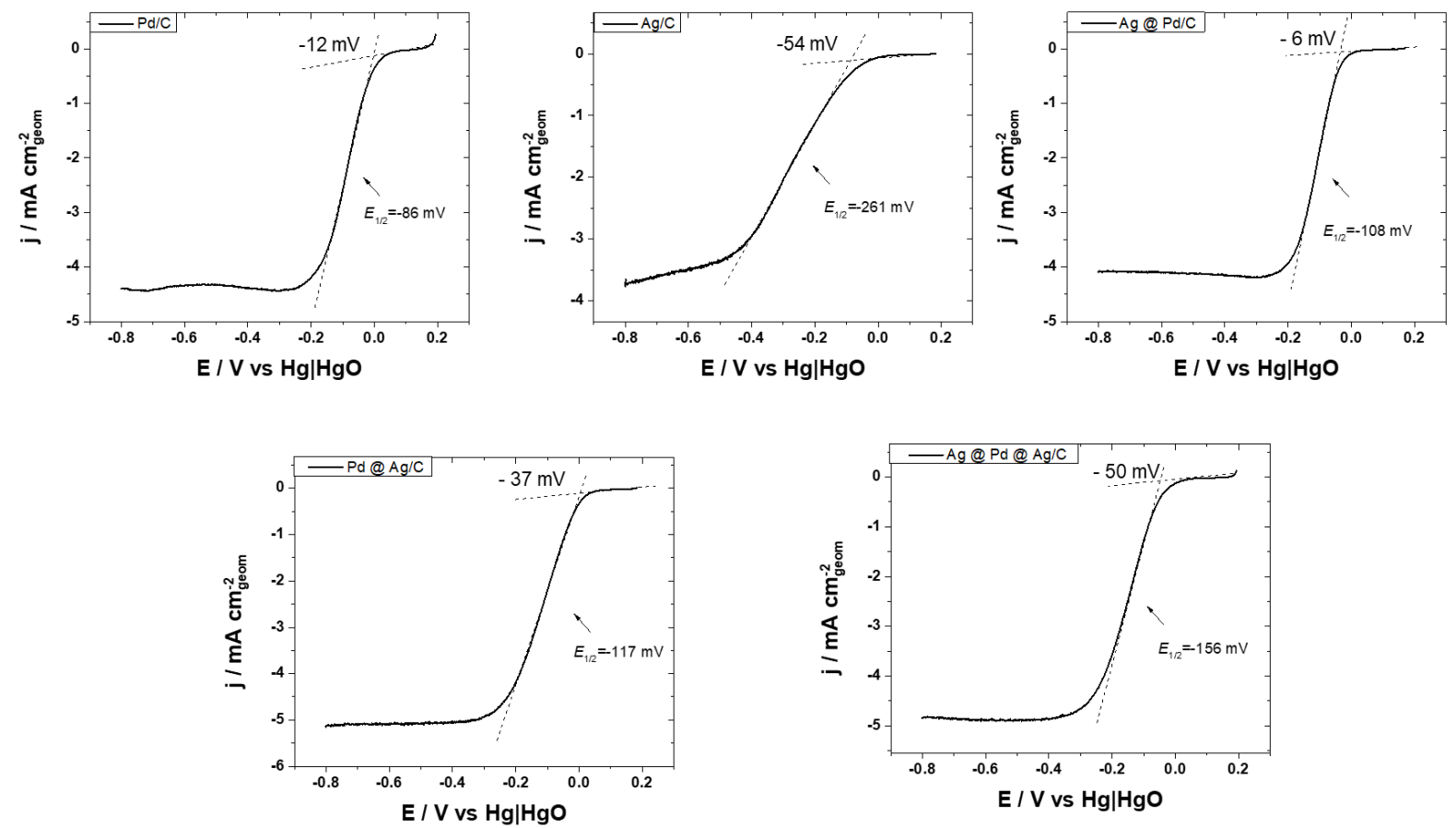

Figure S2: Determination of the ORR RDE kinetic parameters of catalysts.

Kinetic parameters for the oxygen reduction reaction used to determine the onset potential as well as the half wave potential $\left(E_{1 / 2}\right)$ for each of the catalysts tested at $1600 \mathrm{rpm}$ are shown in the Figure $\mathrm{S} 2$. The onset potential was determined by the intercepting line in the polarization curve. $\mathrm{E}_{1 / 2}$ is often used to evaluate the electrocatalytic activity of a catalyst. Sweep Rate $=10 \mathrm{mV} \mathrm{s}^{-1}$. 

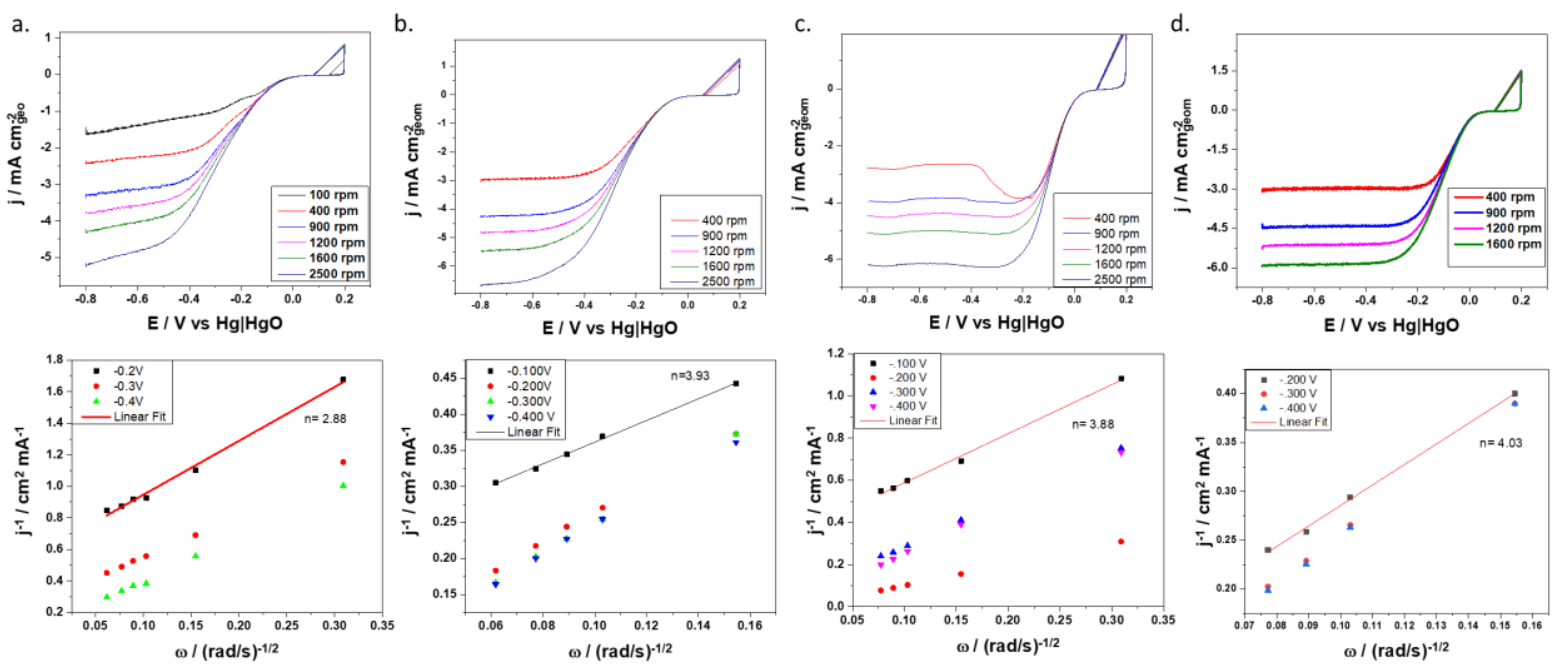

Figure S3: Rotating disk electrode (RDE) measurements of the oxygen reduction reaction catalysts.

RDE measurements of the ORR of (a) Ag/C, (b) Pd/C, (c) Ag @ Pd/C and (d) Pd @ Ag/C electrocatalyst in a $0.1 \mathrm{M} \mathrm{KOH}$ solution purged by $\mathrm{O}_{2}$ at different rotation speeds (100 to 2500 $\mathrm{rpm})$. The number of transferred electrons were determined from the Koutechy-Levich plot. The $\mathrm{Pd}$ mass activity of the $\mathrm{Pd} @ \mathrm{Ag} / \mathrm{C}$ electrocatalyst at $-0.1 \mathrm{~V}$ vs $\mathrm{Hg} \mid \mathrm{HgO}$ is determined to be 878 $\mathrm{mA} / \mathrm{cm}^{2}$ approximately 2 times higher than commercial $\mathrm{Pd} / \mathrm{C}$ electrocatalyst. Sweep rate $=10 \mathrm{mV}$ $\mathrm{s}^{-1}$. Electrode Area $=0.196 \mathrm{~cm}^{2}$. 
a.

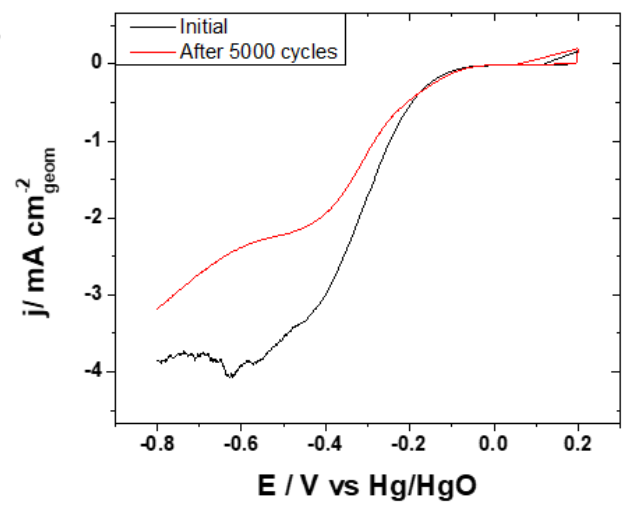

C.

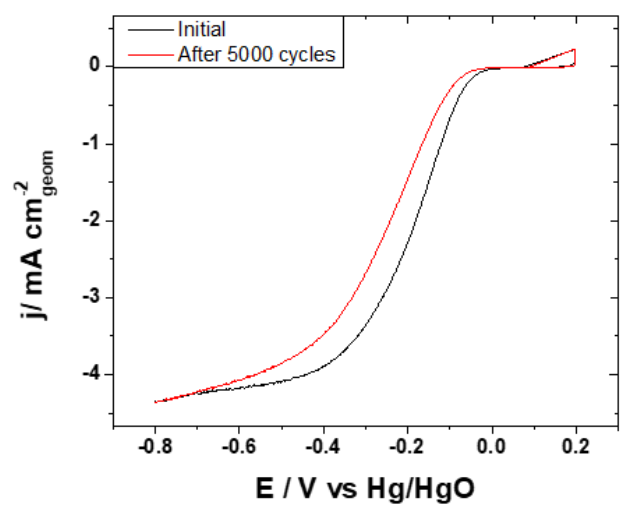

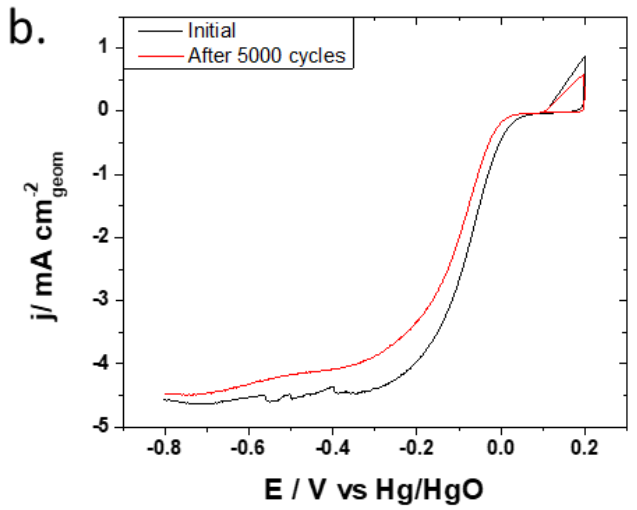

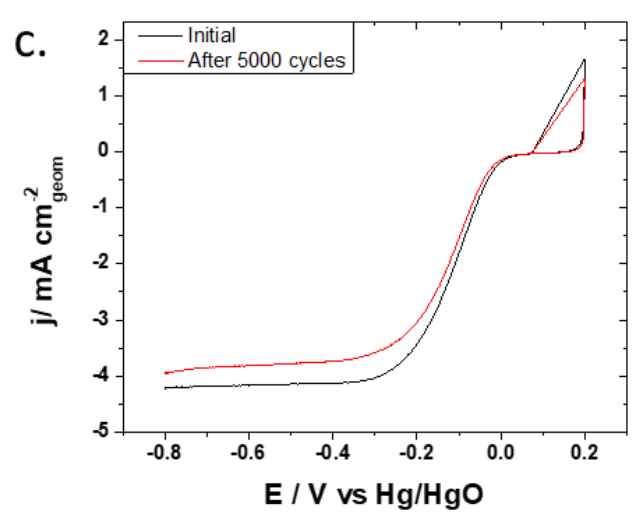

Figure S4: Stability ORR polarization curves of the catalysts after 5000 cycles of $-0.3 \mathrm{~V}-$ 0.1 V vs Hg|HgO.

Stability experiments were done of the ORR polarization curves for (a) $\mathrm{Ag} / \mathrm{C}$, (b) $\mathrm{Pd} / \mathrm{C}$ (c) $\mathrm{Ag} @$ $\mathrm{Pd} / \mathrm{C}$ and (d) Pd @ Ag/C catalyst before and after 5,000 potential cycles at $1600 \mathrm{rpm}$ in $0.1 \mathrm{M}$ $\mathrm{KOH}$ saturated with Ar between 0.2 and $-0.8 \mathrm{~V}$ vs $\mathrm{Hg} \mid \mathrm{HgO}$. Sweep Rate: $10 \mathrm{mV} \mathrm{s}^{-1}$. 


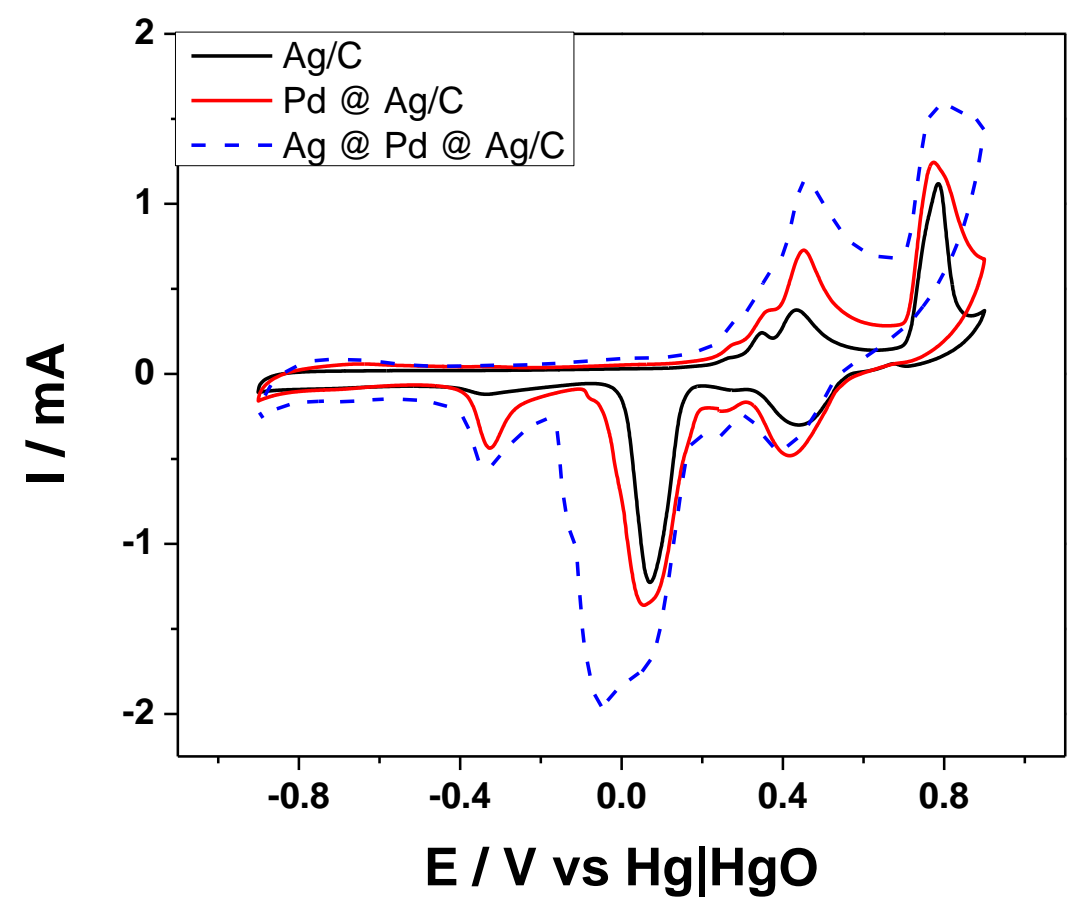

Figure S5: Cyclic voltammetry of Ag/C, Pd @ Ag/C and adding an additional layer of Ag onto Pd @ Ag/C.

Measurements were done in an Ar purged 0.1 M KOH aqueous solution. Sweep Rate: $50 \mathrm{mV} \mathrm{s}{ }^{-1}$. Using the method described in Supporting Information Figure S1, an additional layer of Ag was deposited using $\mathrm{Cu}$ UPD followed by galvanic displacement using a $\mathrm{AgNO}_{3}$ solution. We can observe how the Ag oxidation and Ag oxide reduction peaks become more pronounced. 

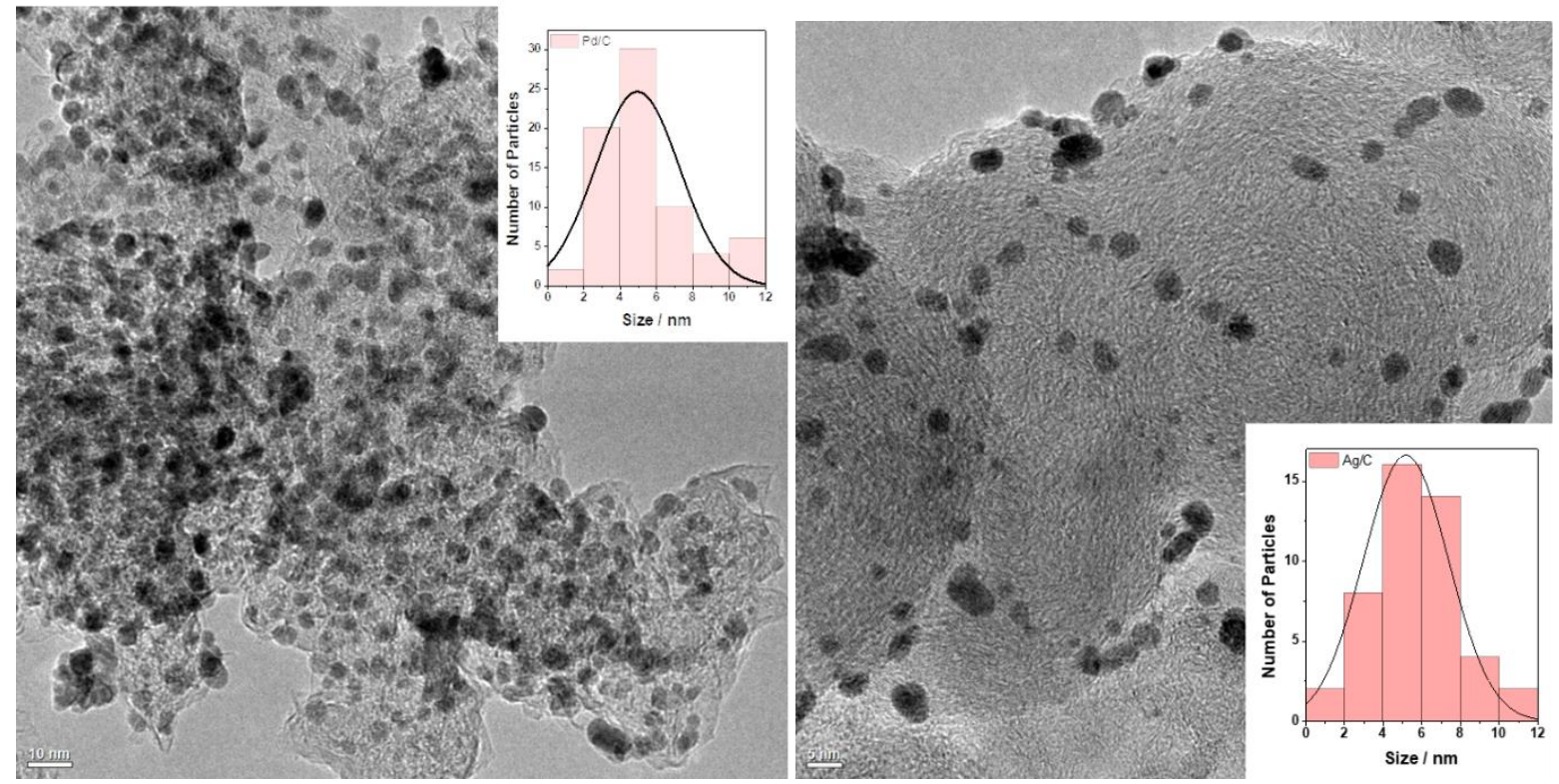

Figure S6: TEM and histogram for (a) $\mathrm{Pd} / \mathrm{C}$ and (b) Ag/C catalysts.

Average $\mathrm{Pd}$ and $\mathrm{Ag}$ nanoparticle size for $\mathrm{Pd} / \mathrm{C}$ and $\mathrm{Ag} / \mathrm{C}$ was 5.1 and $5.6 \mathrm{~nm}$ respectively 


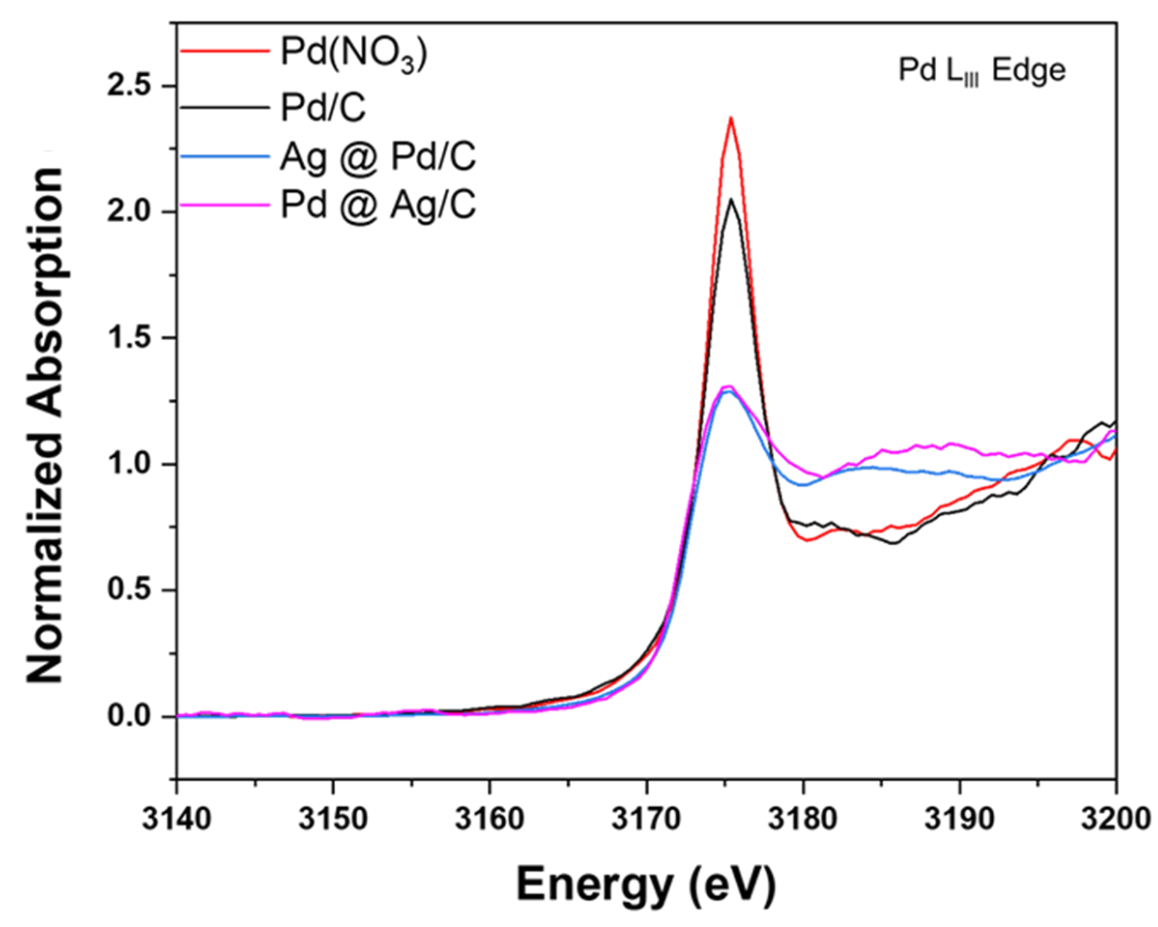

Figure S7: Pd L3-edge XANES data for the alloys shown together with $\mathrm{Pd} / \mathrm{C}$ and $\mathrm{Pd}\left(\mathrm{NO}_{3}\right)_{2}$ used as standard.

The elements, spectra normalized and calibrated relative to the threshold where PdAg bimetallic exhibit reduced white line intensity compared to the $\mathrm{Pd}^{2+}$ used as a standard and $\mathrm{Pd} / \mathrm{C}$. The spectra were collected at NSLS-II (8-ID). 


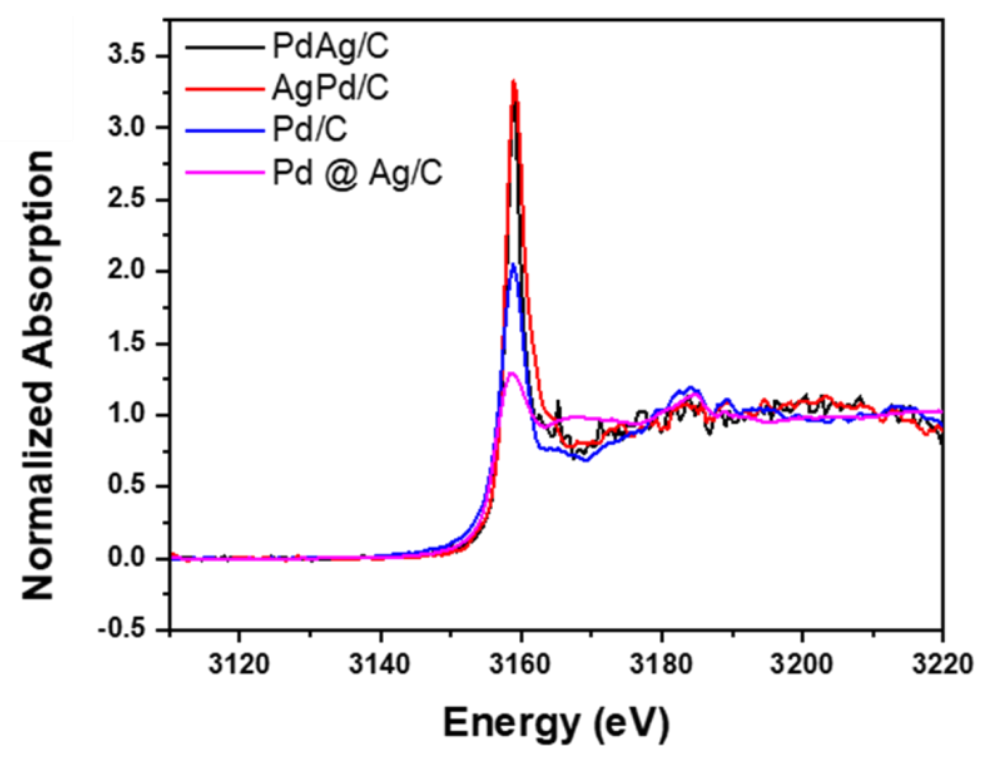

Figure S8: Pd L3-edge XANES for the synthesized alloys of PdAg/C and AgPd/C without the Cu upd treatment relative to $\mathrm{Pd} / \mathrm{C}$ and Pd @ Ag/C.

The WL intensity for the synthesis without $\mathrm{Cu}$ UPD has sharper white line intensity whereas the alloy prepared by $\mathrm{Cu}$ UPD exhibits an attenuation of the white line due to intimate Pd-Ag interaction confirming an alloy formation. Spectra were collected at NSLS-II (8-ID).
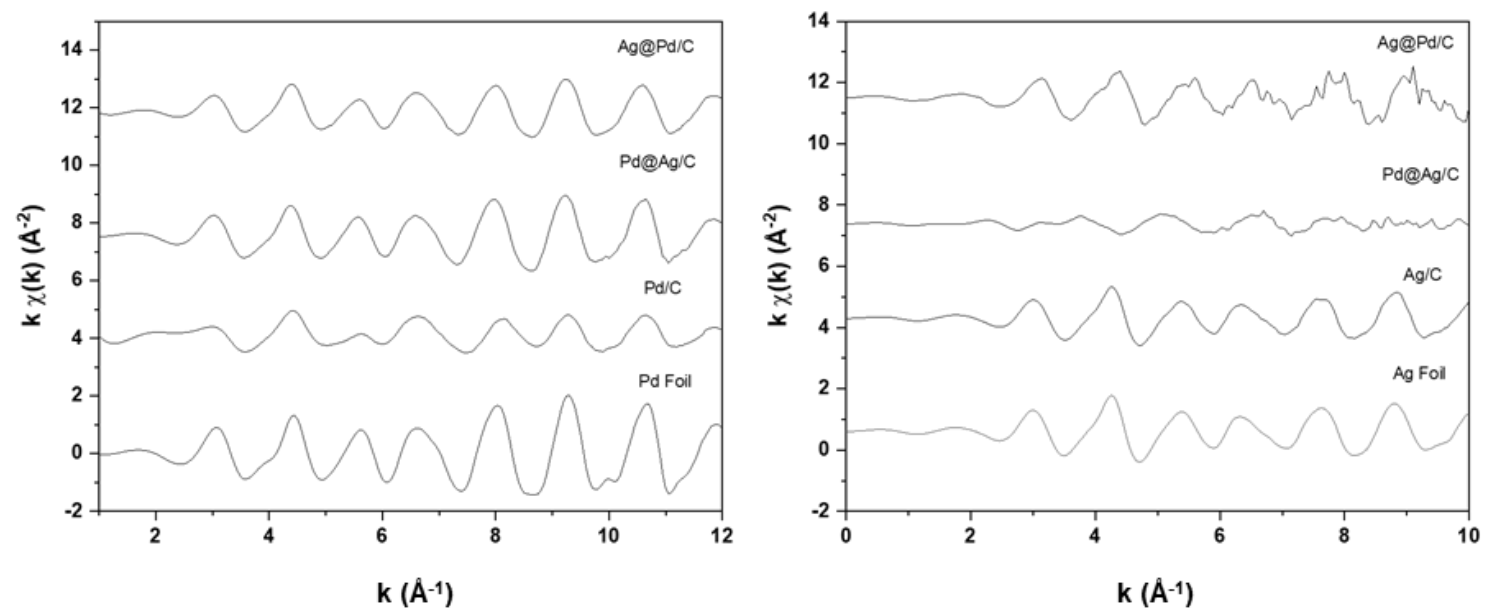

Figure S9: XAFS data for (a) Pd edge and (b) Ag edge for all the catalysts examined 


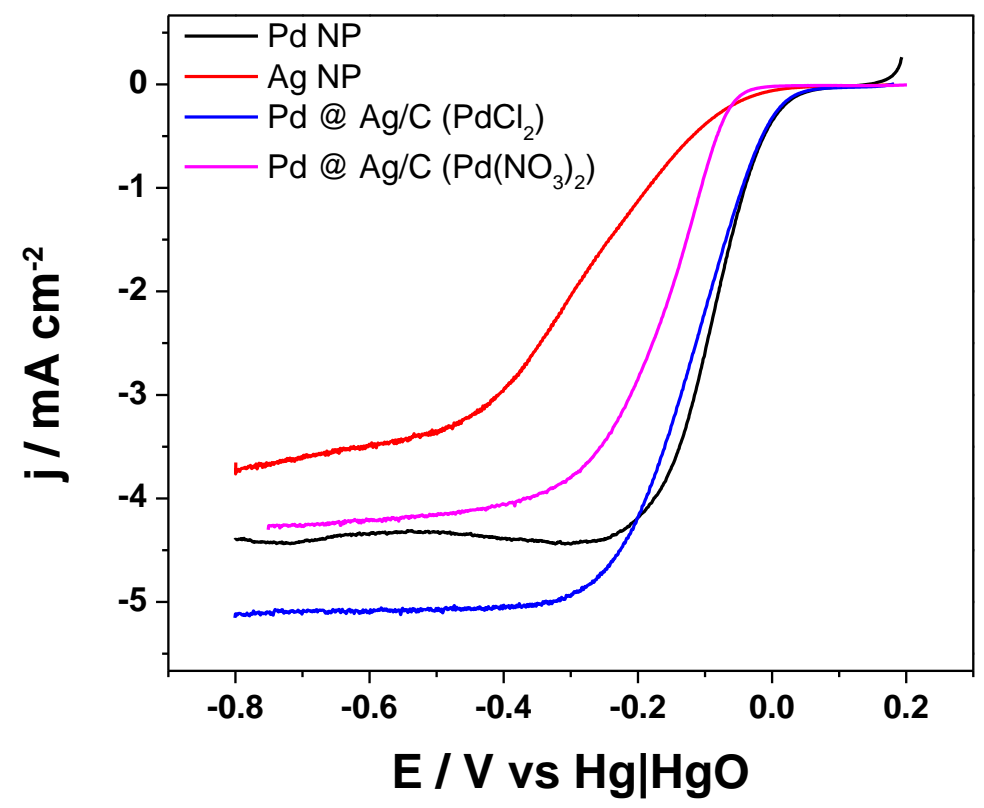

Figure S10: Rotating disk electrode (RDE) measurements of the oxygen reduction reaction (ORR).

Rotating disk electrode (RDE) measurements of the oxygen reduction reaction (ORR) of (a) $\mathrm{Pd} / \mathrm{C}$, (b) $\mathrm{Ag} / \mathrm{C}$, (c) $\mathrm{Pd} @ \mathrm{Ag} / \mathrm{C}$, using a $\mathrm{PdCl}_{2}$ precursor, and (d) $\mathrm{Pd} @ \mathrm{Ag} / \mathrm{C}$, using a $\mathrm{Pd}(\mathrm{NO})_{3}$ precursor, in a $0.1 \mathrm{M} \mathrm{KOH}$ solution purged by $\mathrm{O}_{2}$ at different rotation speeds $1600 \mathrm{rpm}$. Sweep rate $=10 \mathrm{mV}$ $\mathrm{s}^{-1}$. Electrode Area $=0.196 \mathrm{~cm}^{2}$. 

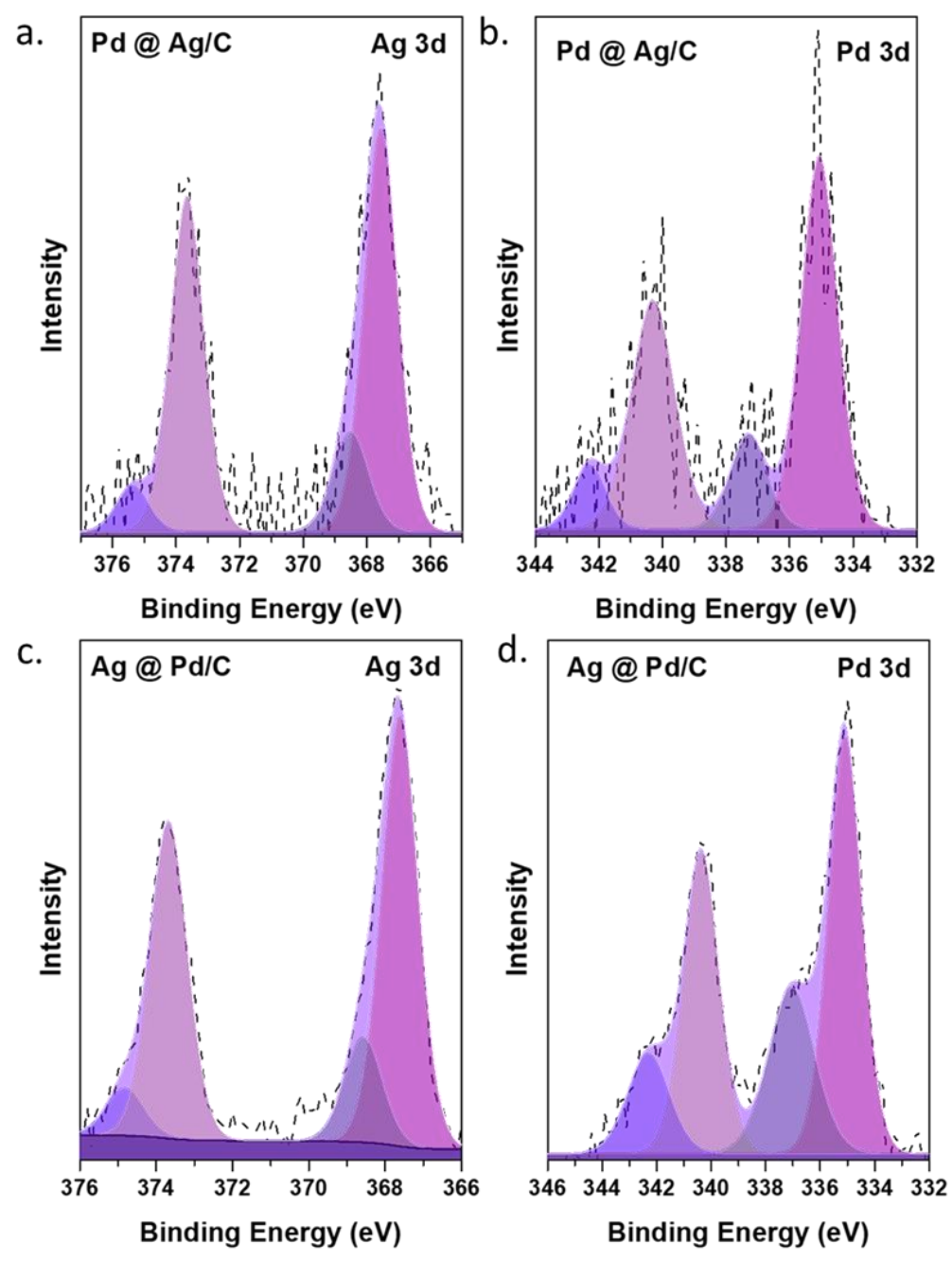

Figure S11: Peak fitting of X-ray photoelectron spectroscopy of Ag 3d and Pd 3d binding energy peaks.

Ag 3d and Pd 3d XPS binding energy peaks fitting using the area under the curve which is proportional to elemental concentration at the probing depth of the X-ray source $(\mathrm{Mg} \mathrm{K}$-alpha, $1253.6 \mathrm{eV}$ ) for Ag @ Pd/C (a) Ag 3d (b) Pd 3d and Pd @ Ag/C (c) Ag 3d and (d) Pd 3d. Using a XPS curve fitting, the elemental concentration (Ag:Pd) ratio at the surface was calculated to be 2:1 for $\mathrm{Pd} @ \mathrm{Ag} / \mathrm{C}$ and 1:1 for $\mathrm{Ag} @ \mathrm{Pd} / \mathrm{C}$. 